\title{
A Capture Strategy for the Identification of Thio-Templated Metabolites
}

\author{
Lauren A. Washburn, Keshav K. Nepal, and Coran M. H. Watanabe* \\ Department of Chemistry, Texas A\&M University, College Station, Texas 77843, United States \\ Azinomycin, nonribosomal peptide, polyketide, natural products
}

\begin{abstract}
Nonribosomal peptide synthetase and polyketide synthase systems are home to complex enzymology and produce compounds of great therapeutic value. Despite this, they have continued to be difficult to characterize due to their substrates remaining enzyme-bound by a thioester bond. Here we have developed a strategy to directly trap and characterize the thioester-bound enzyme intermediates and applied the strategy to the azinomycin biosynthetic pathway. The approach was initially applied in vitro to evaluate its efficacy and subsequently moved to an in situ system, where a protein of interest was isolated from the native organism to avoid needing to supply substrates. By isolating the nonribosomal peptide synthetase AziA3 from Streptomyces sahachiroi, the capture strategy revealed AziA3 functions in the late stages of epoxide moiety formation of the azinomycins. The strategy was further validated in vitro with a nonribosomal peptide synthetase involved in colibactin biosynthesis. In the long term, this method will not only be utilized to characterize thioester bound metabolites within the azinomycin biosynthetic pathway, but other cryptic metabolite pathways as well.
\end{abstract}




\section{Table of Contents}

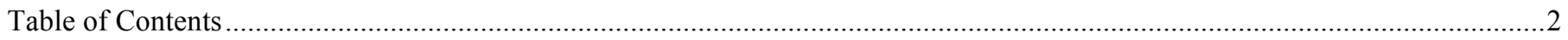

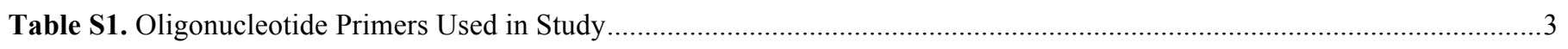

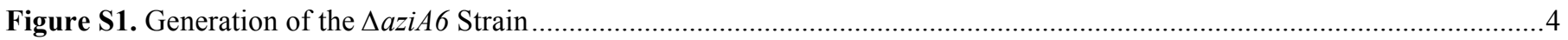

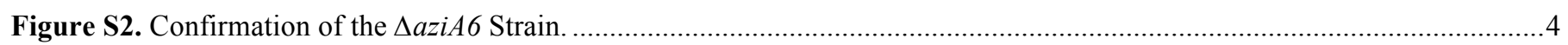

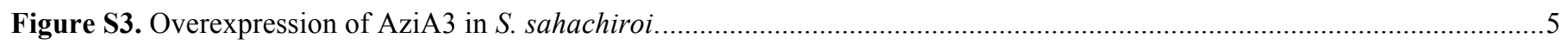

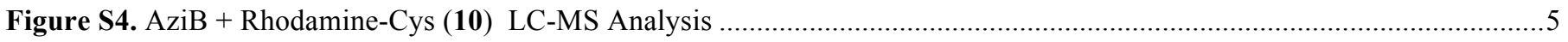

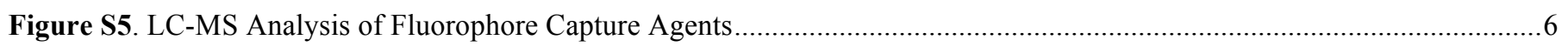

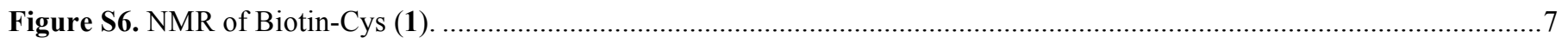

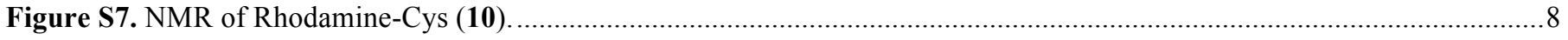

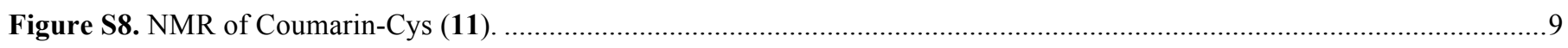

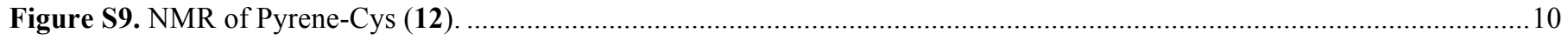

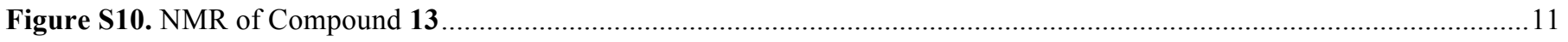

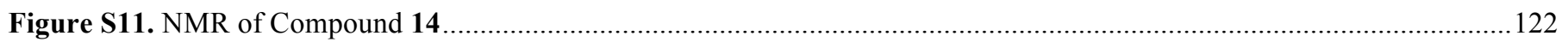

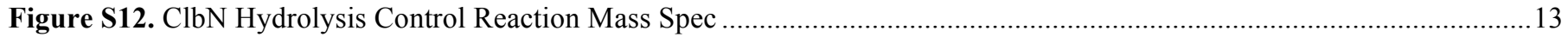

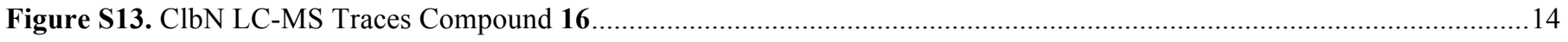

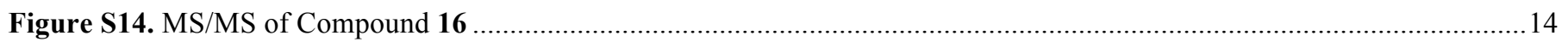

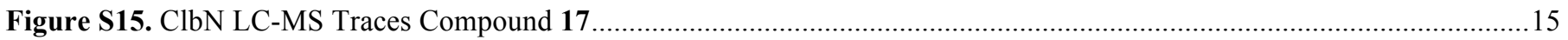

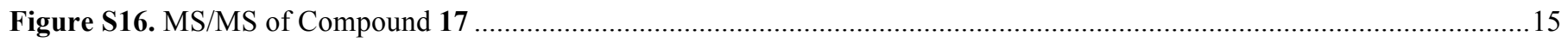

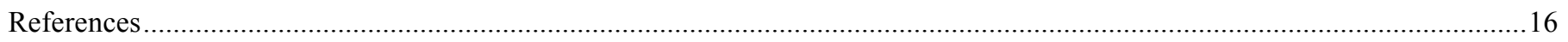

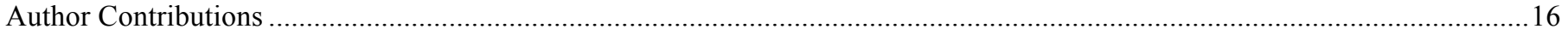


Table S1. Oligonucleotide Primers Used in Study

\begin{tabular}{|l|l|l|l|}
\hline Primer & Sequence (5'-3') & Primer & Sequence (5'-3') \\
\hline AziA6UF & TCAAGCTTCACACGAGCGAGAACGCG & AprF & CGAATGGCGAAAAGCCGAGC \\
AziA6UR & GTCTAGAGGAAGGACCTCTTCGTGA & AprR & GCATCGCATTCTTCGCATCC \\
AziA6DF & ATCTAGACGTGCTCAACGCGTCCCC & AziA6F & GTCAAGCTTATGGACTCGCCCTGGGT \\
AziA6DR & CAGGATCCCGAGAACTATCCCGACCT & AziA6R & GAGCTCGAGCGAAGAGGTCCTTCCG \\
AziA6SBF & ATCGTCAACCTGCTCACCTC & AziA3F & TGGTGACCTCACGGATAGAG \\
AziA6SBR & GCCAGGAACACGTCCCGG & AziA3R & CCCAGGCTGAAGAACGAGT \\
AziA6RTF & TTCCGATCACCACGGTTCG & AziA4F & CCGACGAGGAGAACAGCAC \\
AziA6RTR & TGAGTCCGACGACGAAGTAG & AziA4R & GTGGGAGTGGCGAAGAAGTC \\
pSETAziA3F & TCAGATCTAGGAGGCTCTTCGTGACCACCGCCACCAGC & AziBF & CGCGGGGGCGCAGAGCGCCG \\
pSETAziA3R & TCTAGAAATTCAGTGGTGGTGGTGGTGGTGGCCGGCGATCCAGGCCGCCAG & AziBR & CCCGGCCGCGGCCGCGACGG \\
\hline
\end{tabular}


Figure S1. Generation of the $\triangle a z i A 6$ Strain
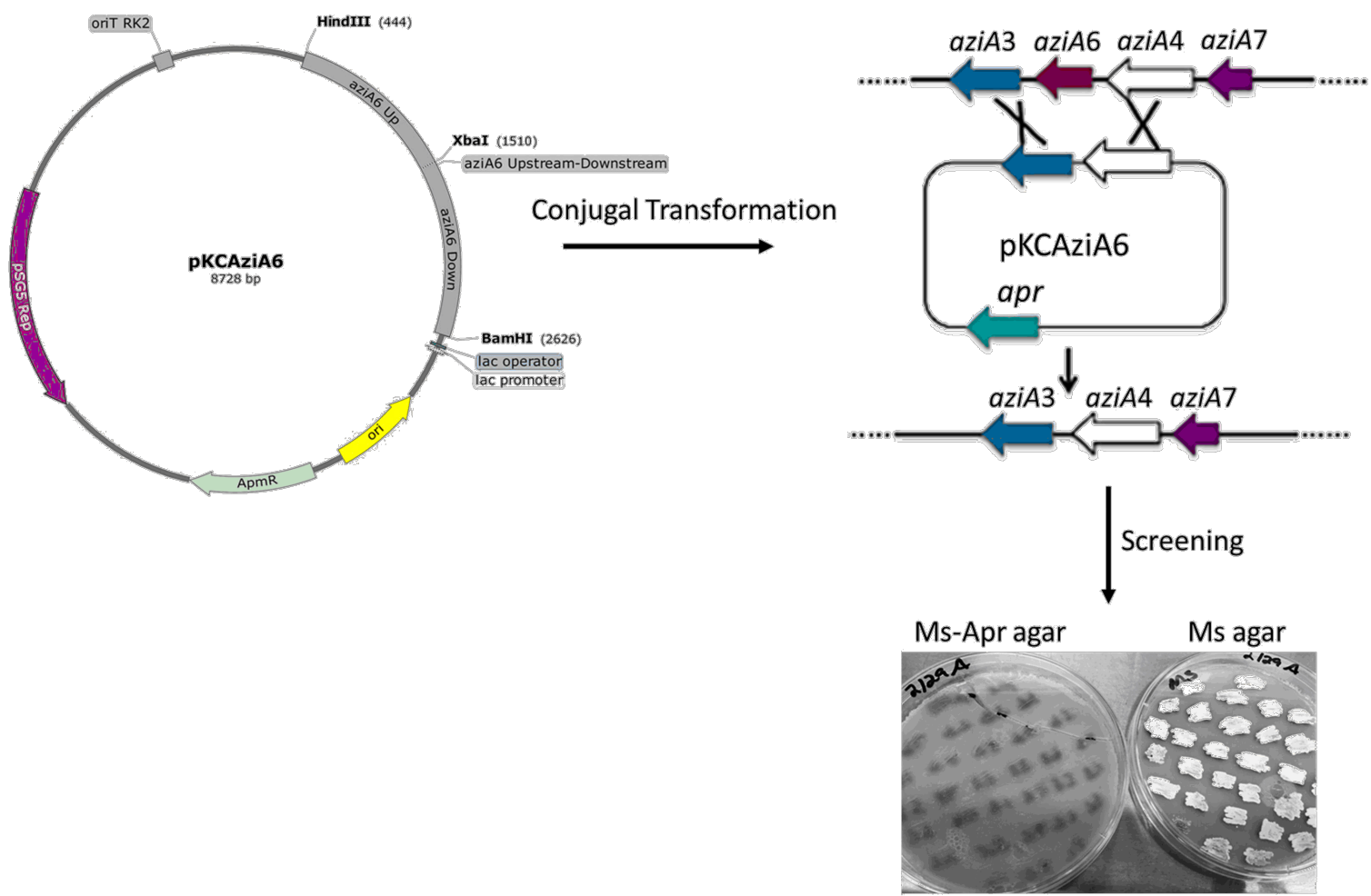

Figure S2. Confirmation of the $\triangle a z i A 6$ Strain.

\section{Southern Blot}

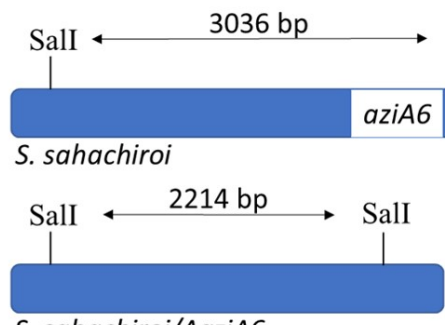

S. sahachiroi/_aziA6

\section{PCR Screening}

Screening for apr

W.T. Ex.Con. $\triangle a z i A 6$

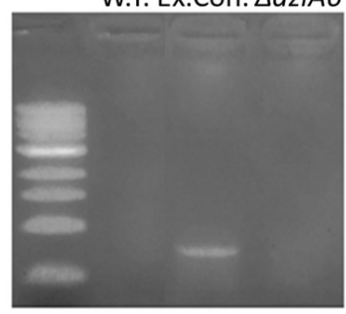

Screening for aziA6

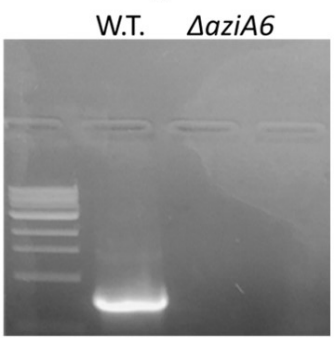

$\triangle a z i A 6$ W.T.

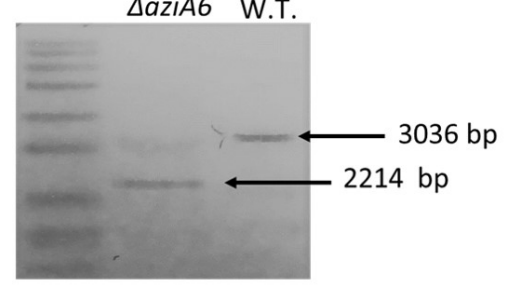

\section{RT-PCR}

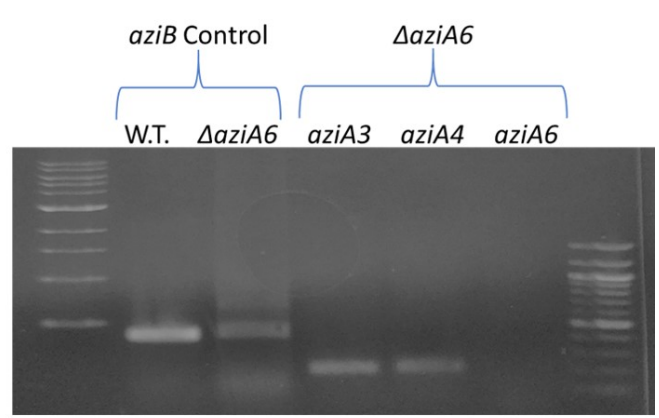


Figure S3. Overexpression of AziA3 in S. sahachiroi.

Plasmid map of pSETAziA3. SDS-PAGE with purified AziA3. M = Marker.
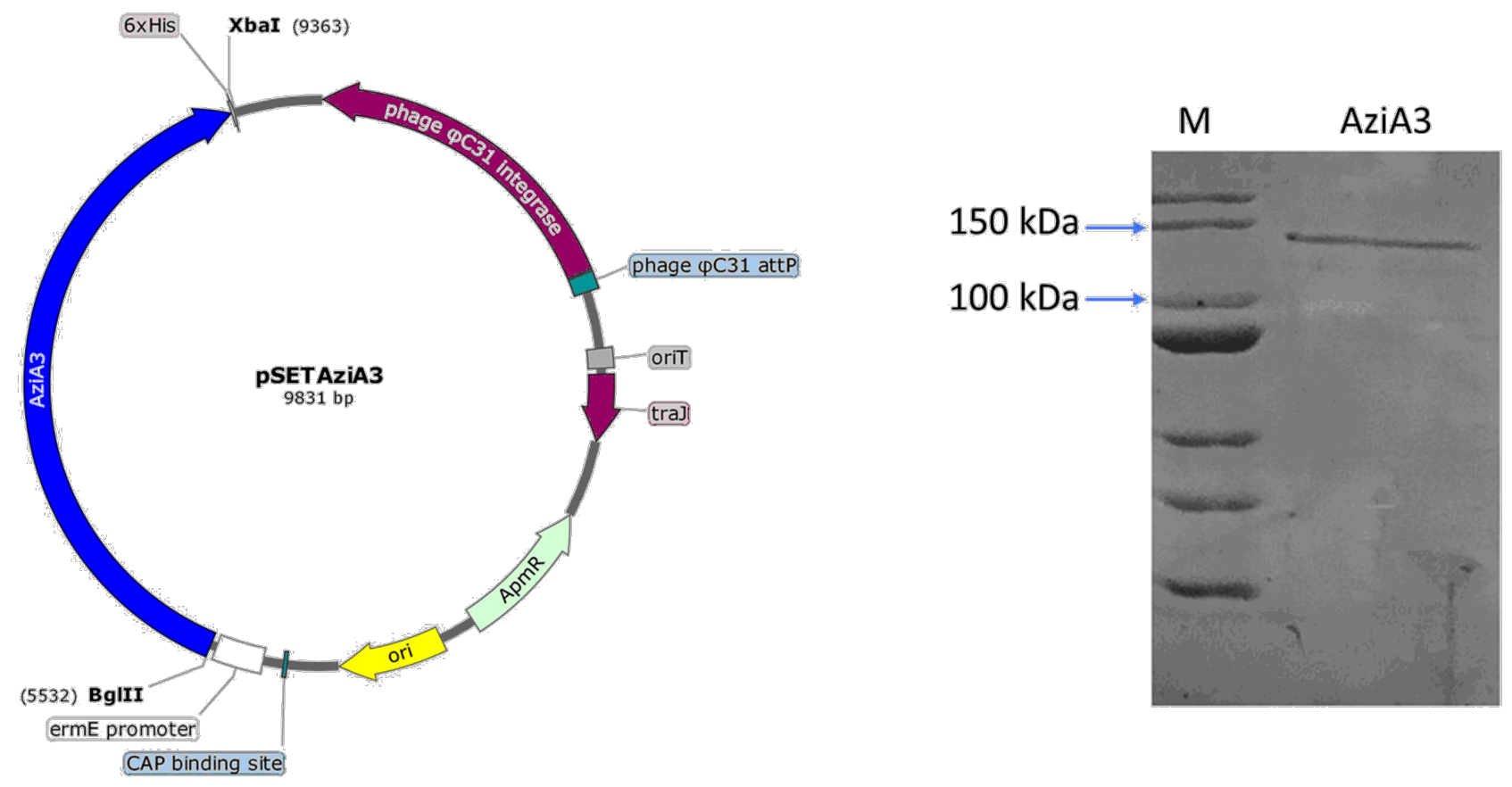

Figure S4. AziB + Rhodamine-Cys (10) LC-MS Analysis

While potential product is observed by mass (red trace), Rhodamine-Cys was not pursued further due to complicated spectra from its instability.

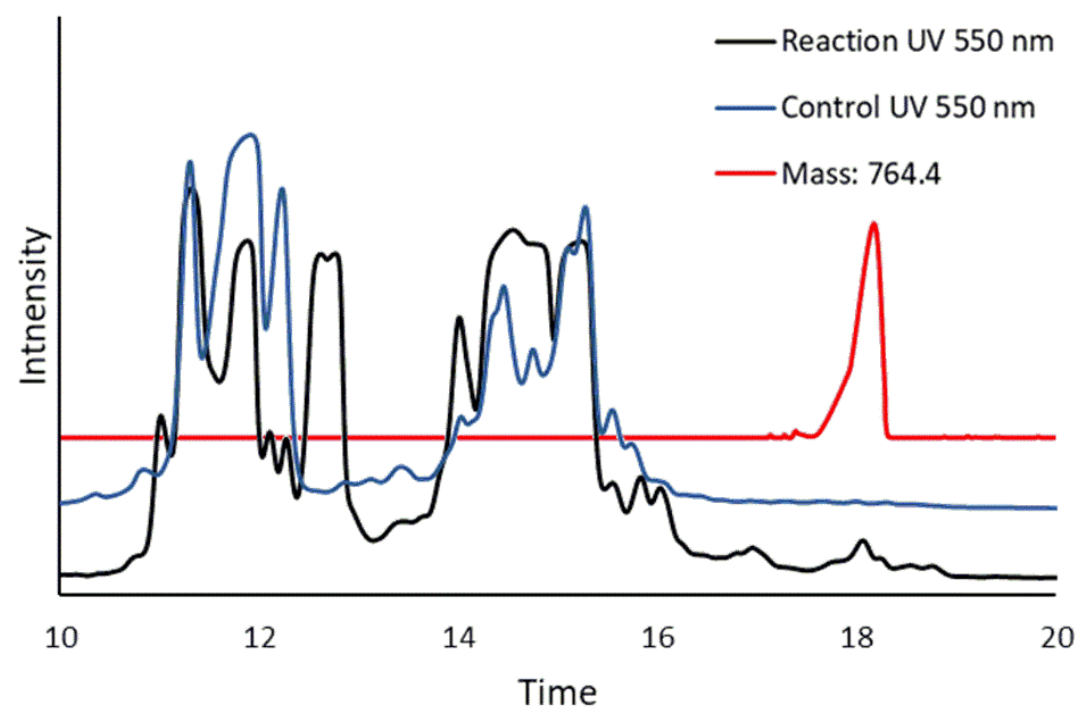


Figure S5. LC-MS Analysis of Fluorophore Capture Agents

Due to the instability observed in the Rhodamine-Cys reaction (Figure S4), the fluorophore capture agents were evaluated for their stability. A) Coumarin-Cys (11). B) Pyrene-Cys (12). C) Rhodamine-Cys (10).

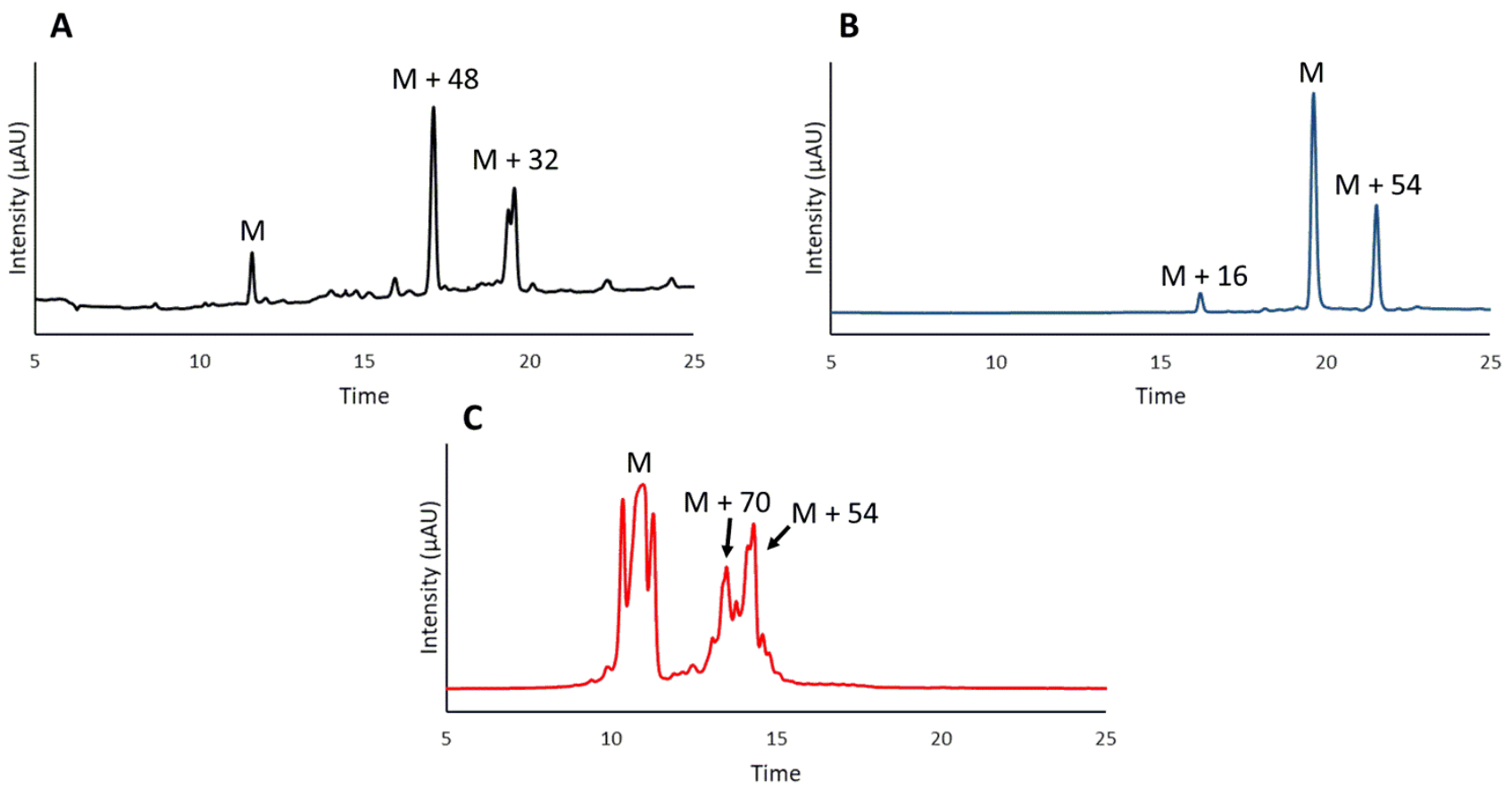


Figure S6. NMR of Biotin-Cys (1).

${ }^{1} \mathrm{H}$ and ${ }^{13} \mathrm{C}\left\{{ }^{1} \mathrm{H}\right\}$ NMR at $400 \mathrm{MHz}$ in $\mathrm{D}_{2} \mathrm{O}$.

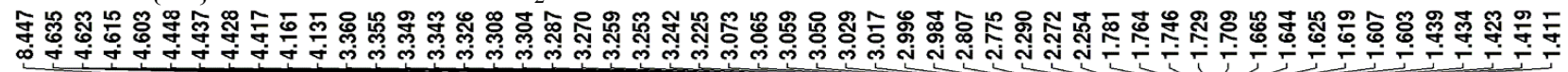

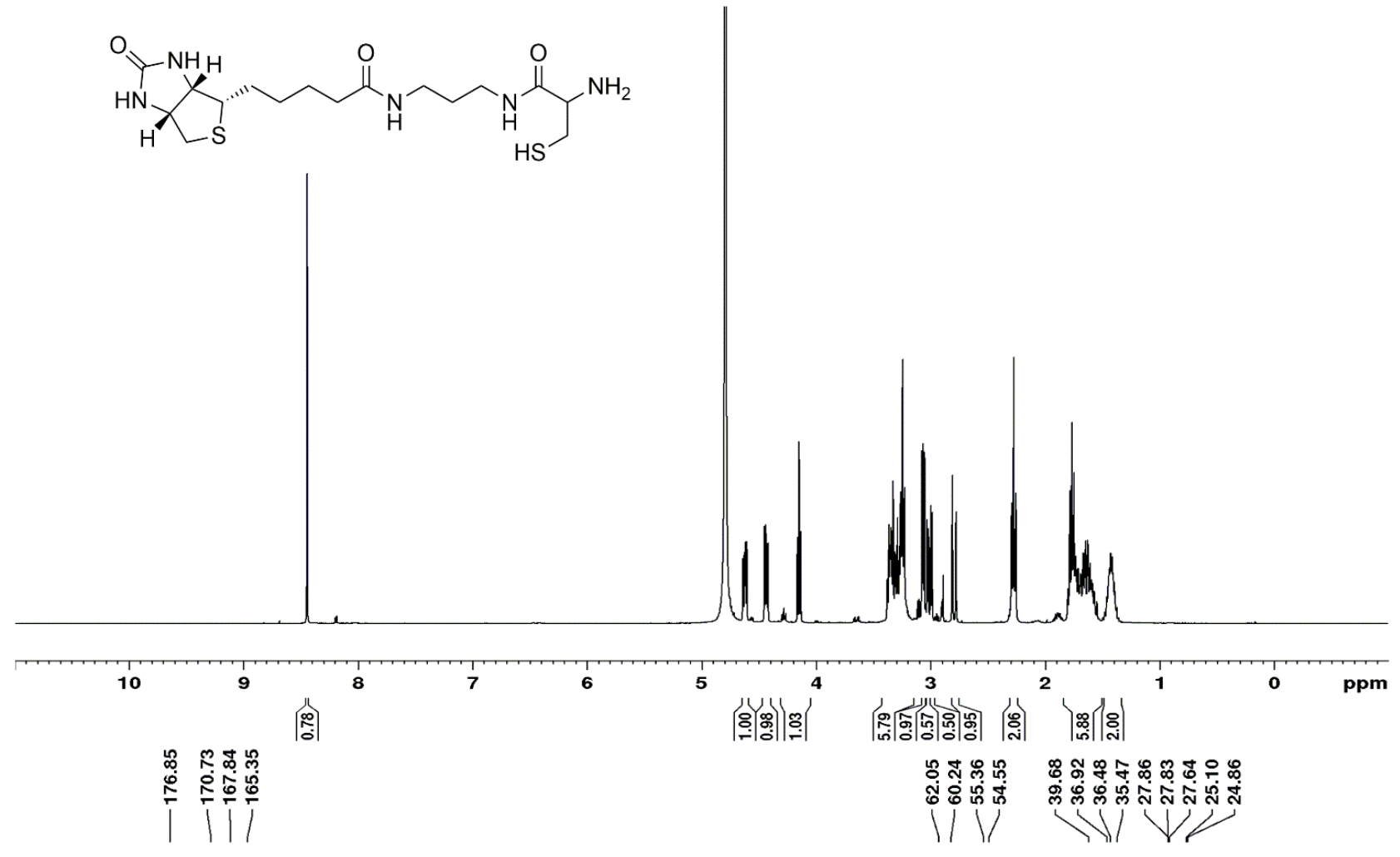<smiles>[CH][C@]12NC(=O)N[C@@H]1CS[C@H]2CCCCC(=O)NCCCNC(=O)C(N)CS</smiles>

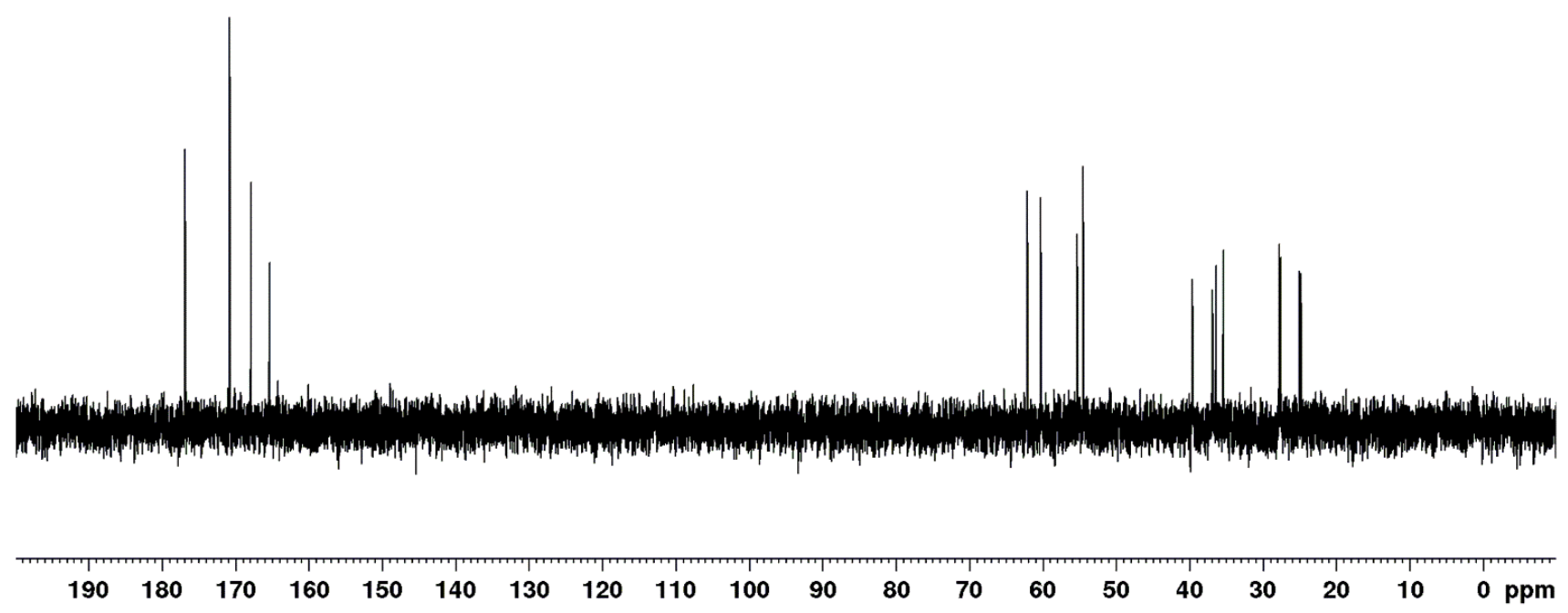


Figure S7. NMR of Rhodamine-Cys (10).

${ }^{1} \mathrm{H}$ and ${ }^{13} \mathrm{C}\left\{{ }^{1} \mathrm{H}\right\} \mathrm{NMR}$ at $400 \mathrm{MHz}$ in $\mathrm{D}_{2} \mathrm{O}$.

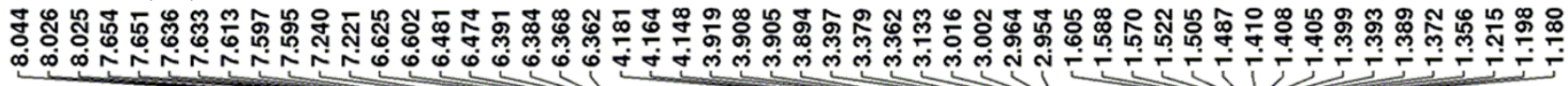

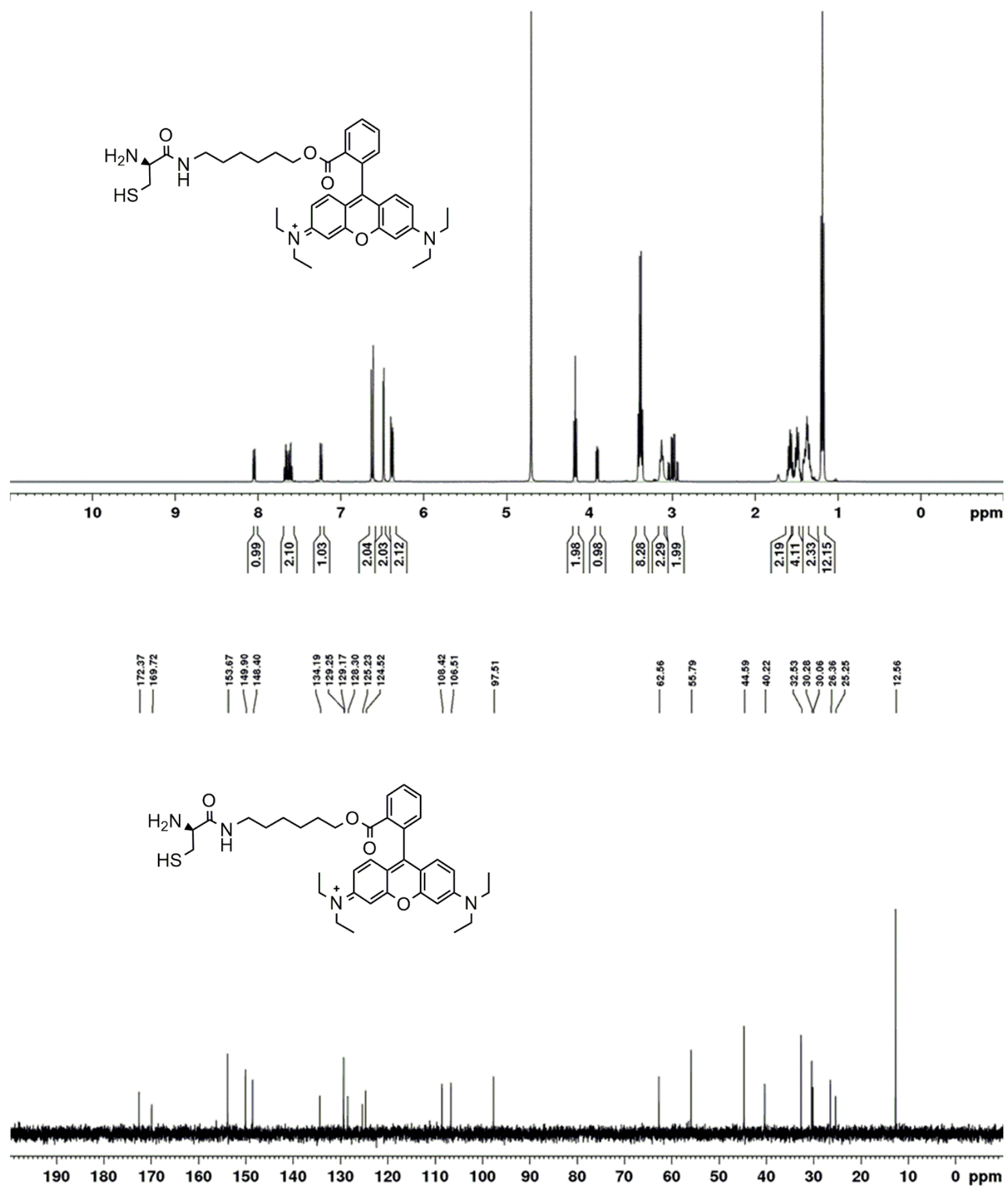


Figure S8. NMR of Coumarin-Cys (11).

${ }^{1} \mathrm{H}$ and ${ }^{13} \mathrm{C}\left\{{ }^{1} \mathrm{H}\right\}$ NMR at $400 \mathrm{MHz}$ in $\mathrm{D}_{2} \mathrm{O}$.

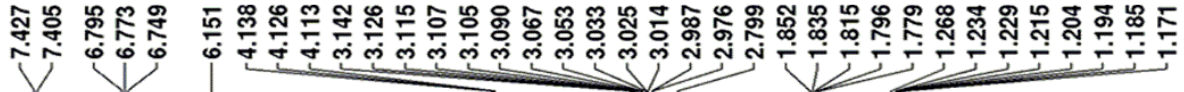
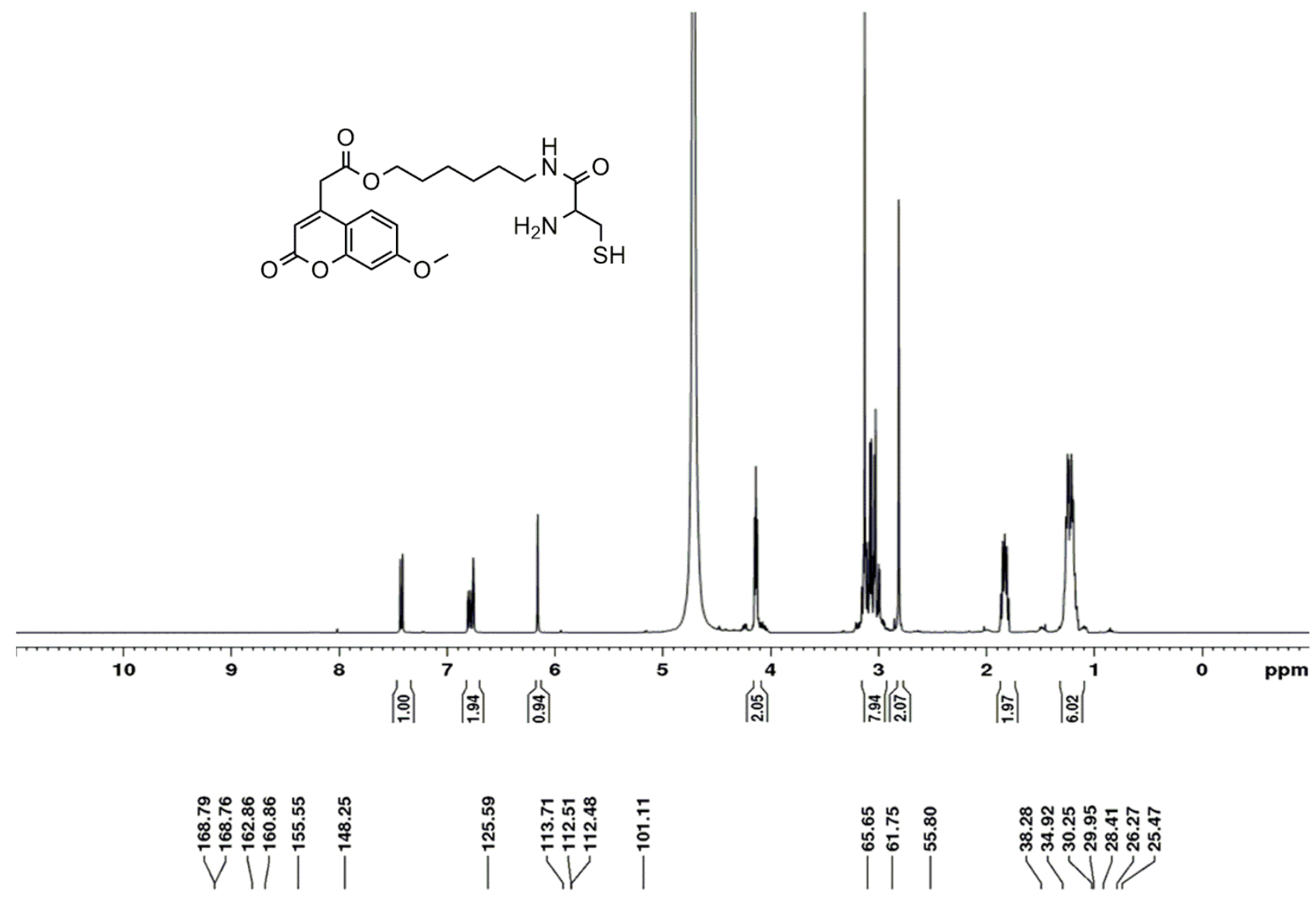<smiles>COc1ccc2c(CC(=O)OCCCCCCNC(=O)C(N)CS)cc(=O)oc2c1</smiles>

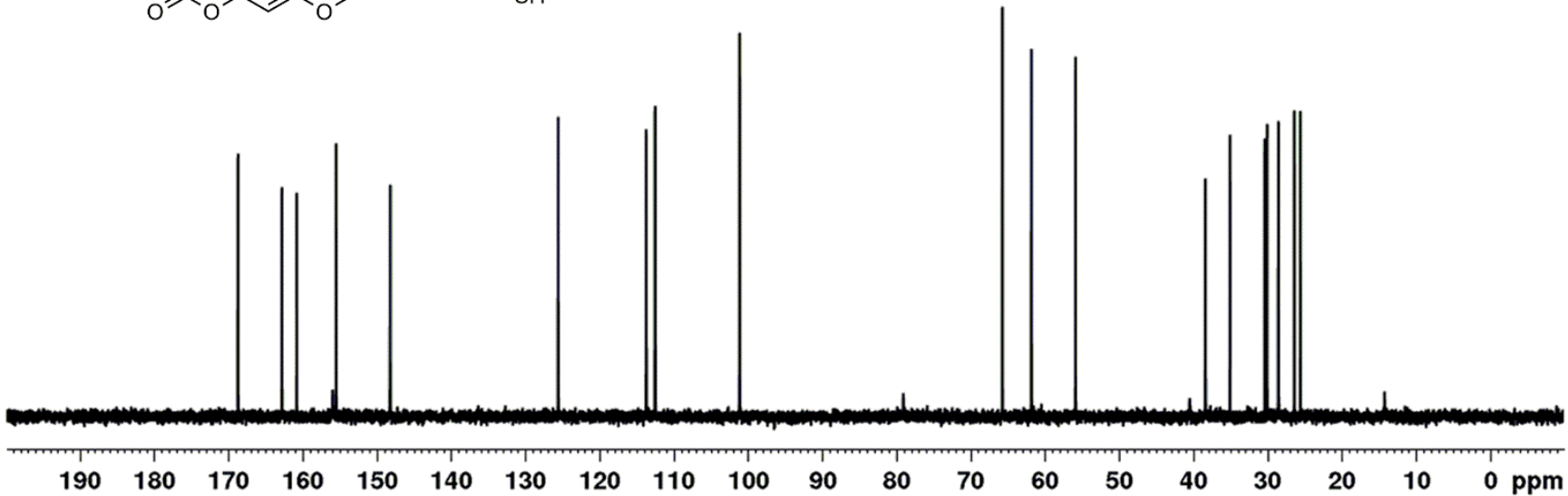


Figure S9. NMR of Pyrene-Cys (12).

${ }^{1} \mathrm{H}$ and ${ }^{13} \mathrm{C}\left\{{ }^{1} \mathrm{H}\right\}$ NMR at $400 \mathrm{MHz}$ in $\mathrm{CD}_{3} \mathrm{OD}$.
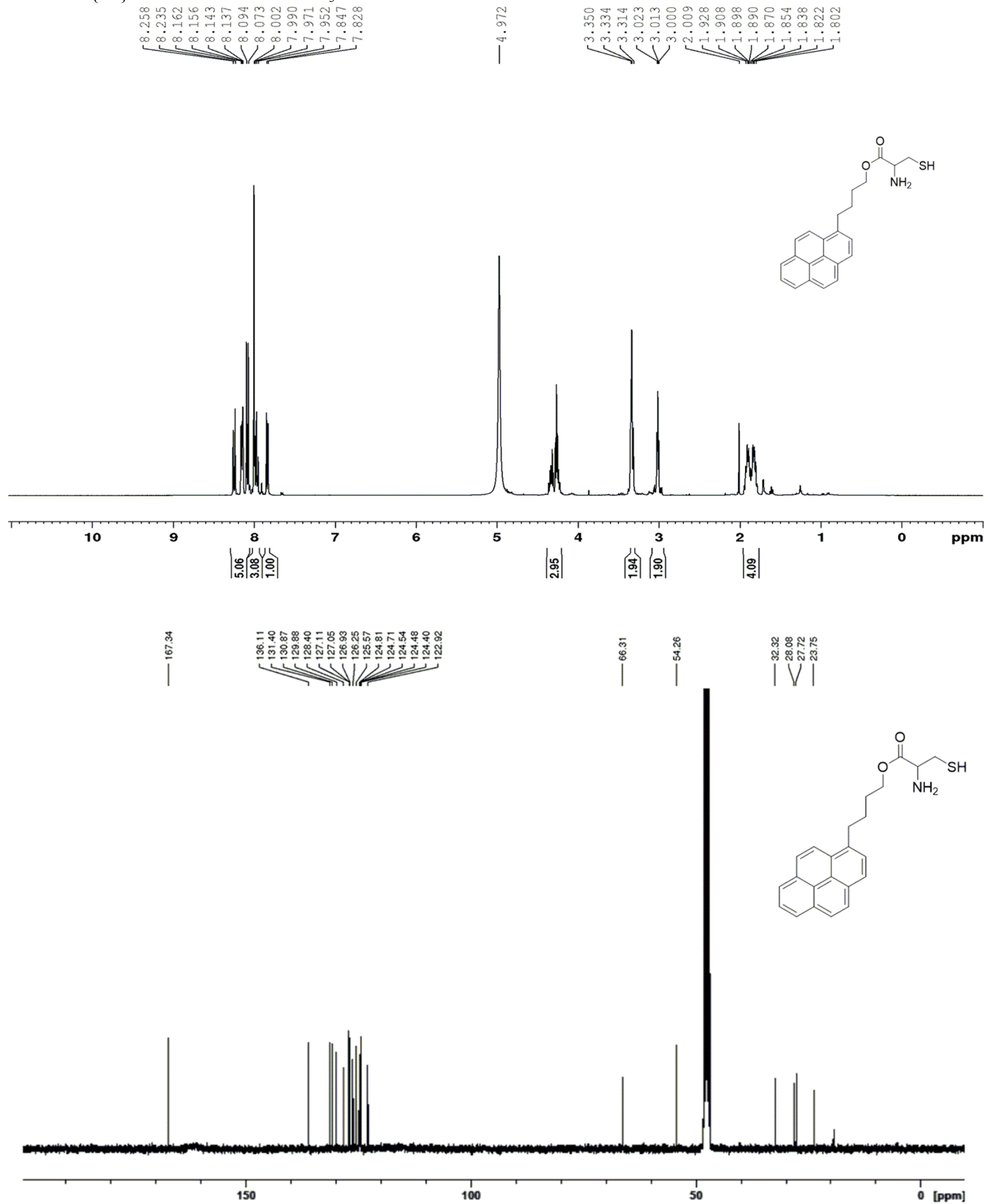
Figure S10. NMR of Compound 13

${ }^{1} \mathrm{H}$ and ${ }^{13} \mathrm{C}\left\{{ }^{1} \mathrm{H}\right\} \mathrm{NMR}$ at $500 \mathrm{MHz}$ in DMSO-D .

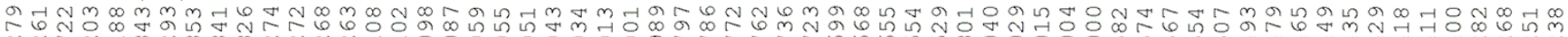

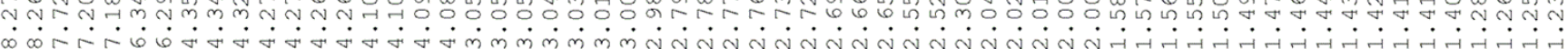

4<smiles>Cc1ccccc1C(=O)NC(CS)C(=O)NCCCNC(=O)CCCC[C@H]1SCC2NC(=O)NC21</smiles>

10

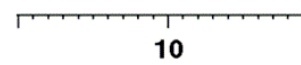

유ำ ำ

ㅅํㅇํํ

IT

$\mathrm{S}_{S}^{\mathrm{O}}$

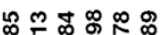

药

KIVIT

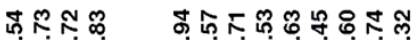

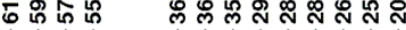

III VIII)

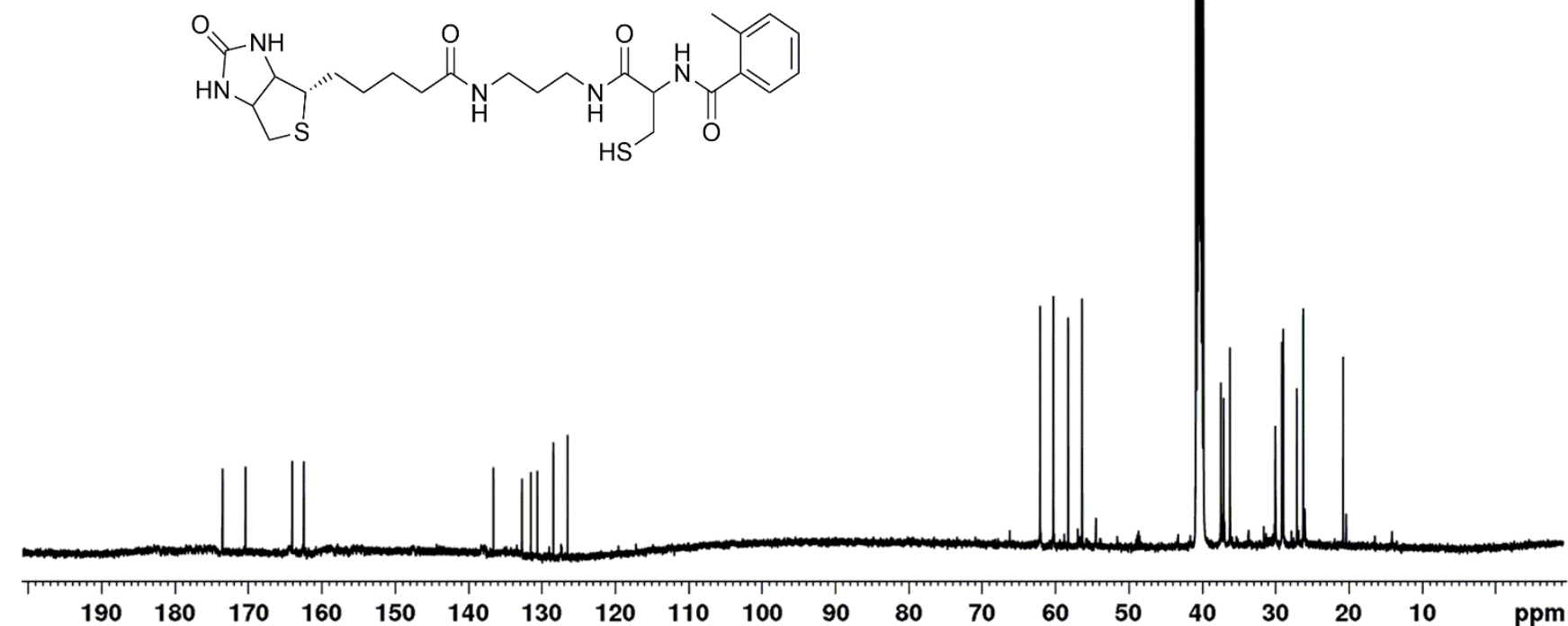


Figure S11. NMR of Compound 14

${ }^{1} \mathrm{H}$ and ${ }^{13} \mathrm{C}\left\{{ }^{1} \mathrm{H}\right\} \mathrm{NMR}$ at $500 \mathrm{MHz}$ in $\mathrm{D}_{2} \mathrm{O} .{ }^{1} \mathrm{H}$ NMR zoomed in to $5 \mathrm{ppm}-1$ ppm for clarity.

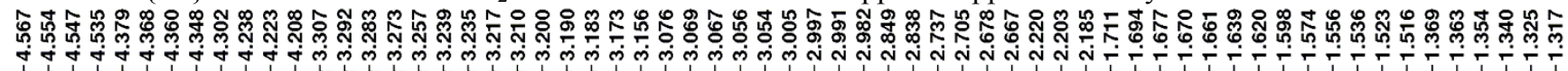

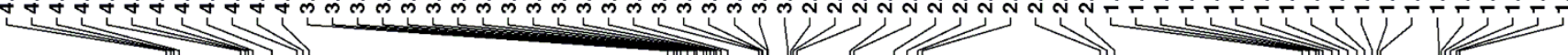

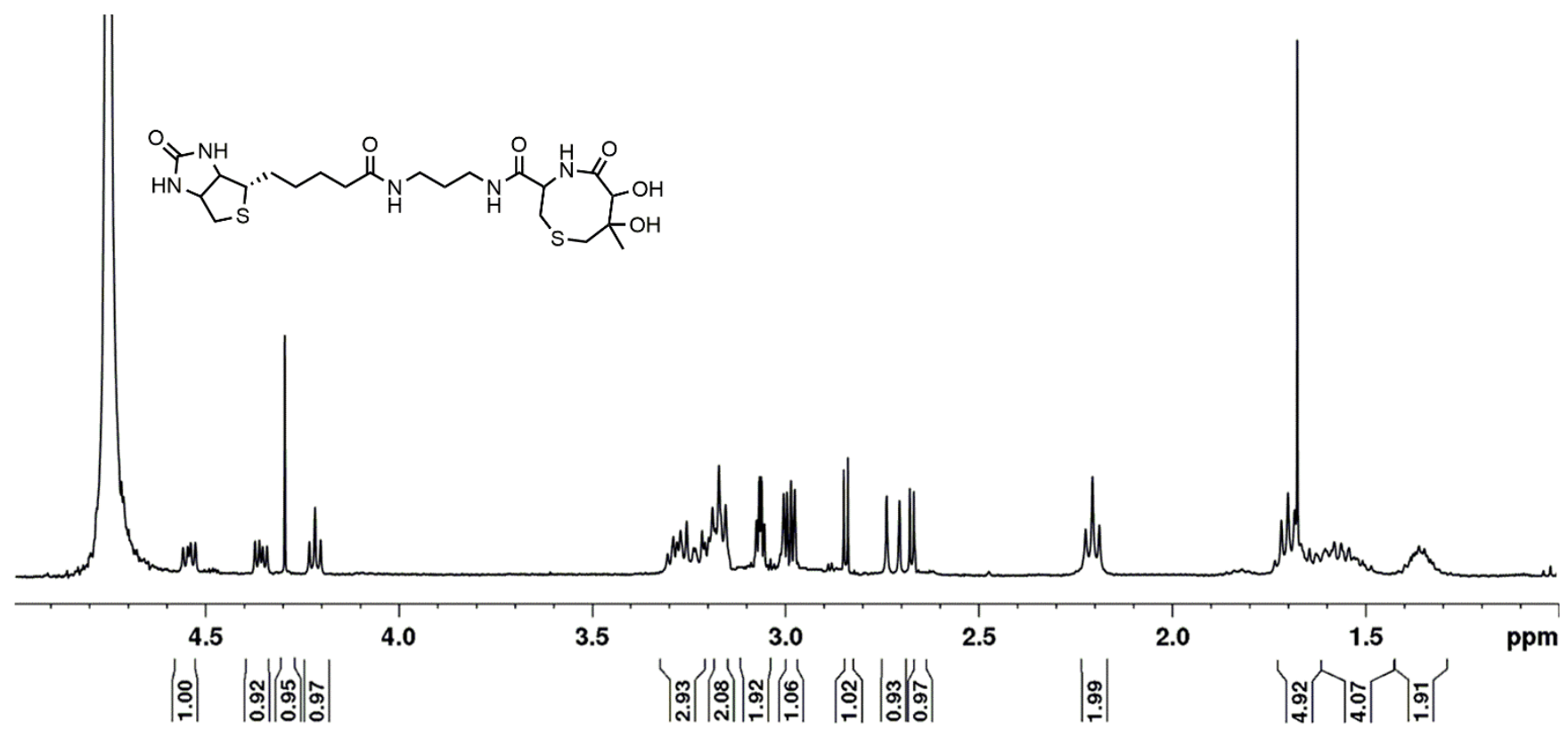

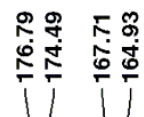

|

$\underbrace{O}_{S}+\cdots{ }^{\mathrm{NH}}$

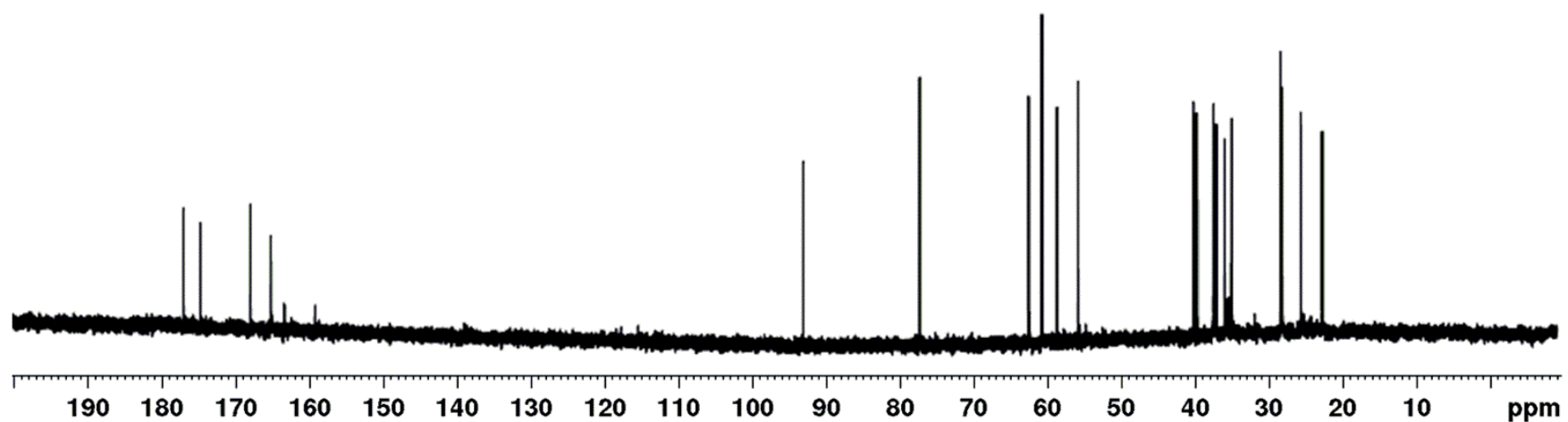


Figure S12. ClbN Hydrolysis Control Reaction Mass Spec

A. ClbN Reaction. B. Synthetic Standard of octanoyl-asparagine. C. Negative Control lacking ClbN protein. Expected product mass of octanoyl-asparagine $m / z[\mathrm{M}+\mathrm{H}]^{+}$calcd for $\mathrm{C}_{12} \mathrm{H}_{22} \mathrm{~N}_{2} \mathrm{O}_{4} ; 259.165$.
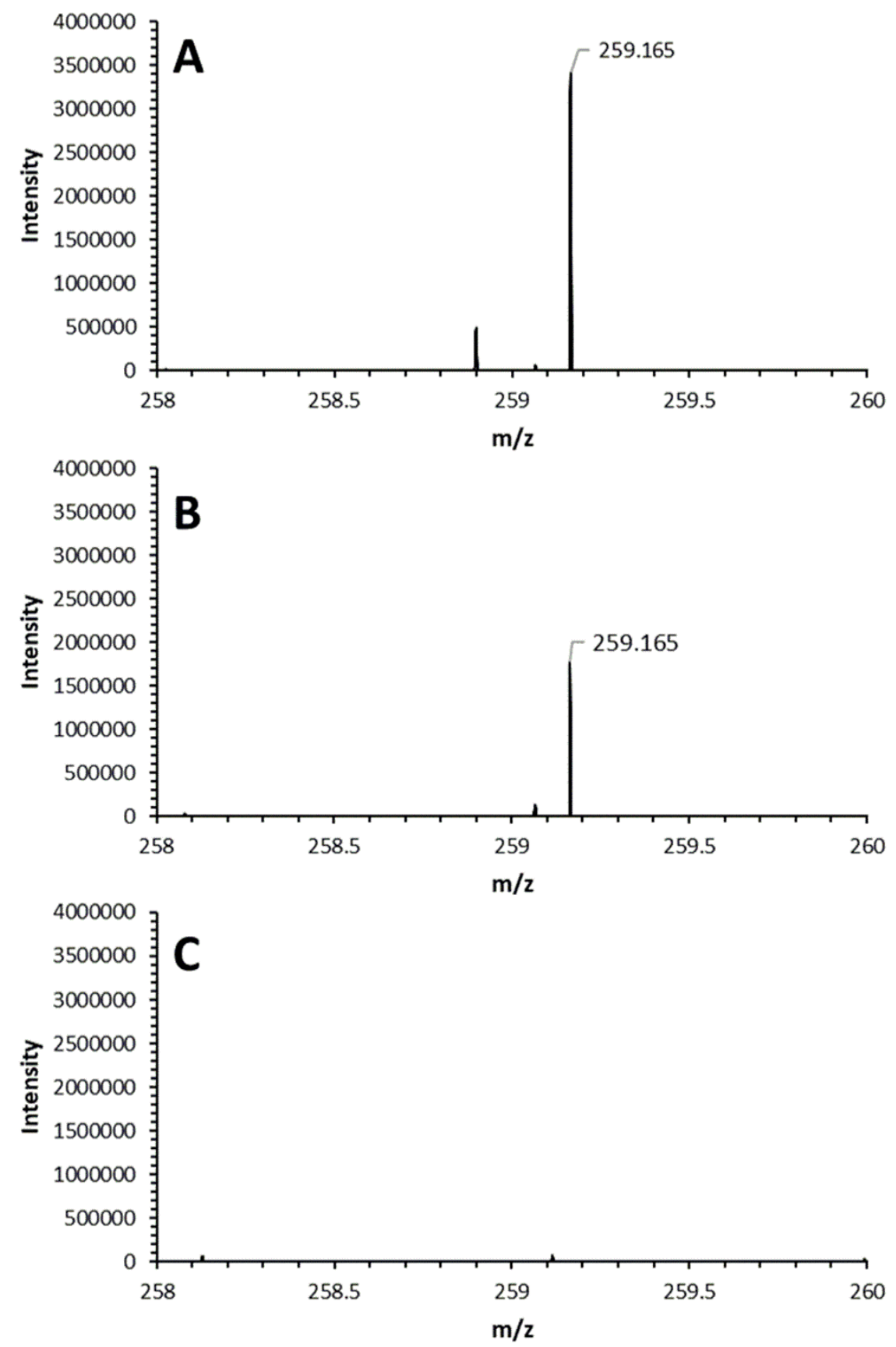
Figure S13. ClbN LC-MS Traces Compound 16

Extraced Ion Chromatograms (EIC) for 644.325. Expected product mass of Compound $16 \mathrm{~m} / z[\mathrm{M}+\mathrm{H}]^{+}$calcd for $\mathrm{C}_{28} \mathrm{H}_{49} \mathrm{~N}_{7} \mathrm{O}_{6} \mathrm{~S}_{2}$; 644.325. A. Biotin-Cys + ClbN Reaction. B. Synthetic Standard of Compound 16. C. Negative Control lacking ClbN protein. D. Overlay of EIC for Biotin-Cys + ClbN Reaction and Synthetic Standard.<smiles>CCCCCCCC(=O)N[C@@H](CC(N)=O)C(=O)NC(CS)C(=O)NCCCNC(=O)CCCC[C@H]1SCC2NC(=O)NC21</smiles>
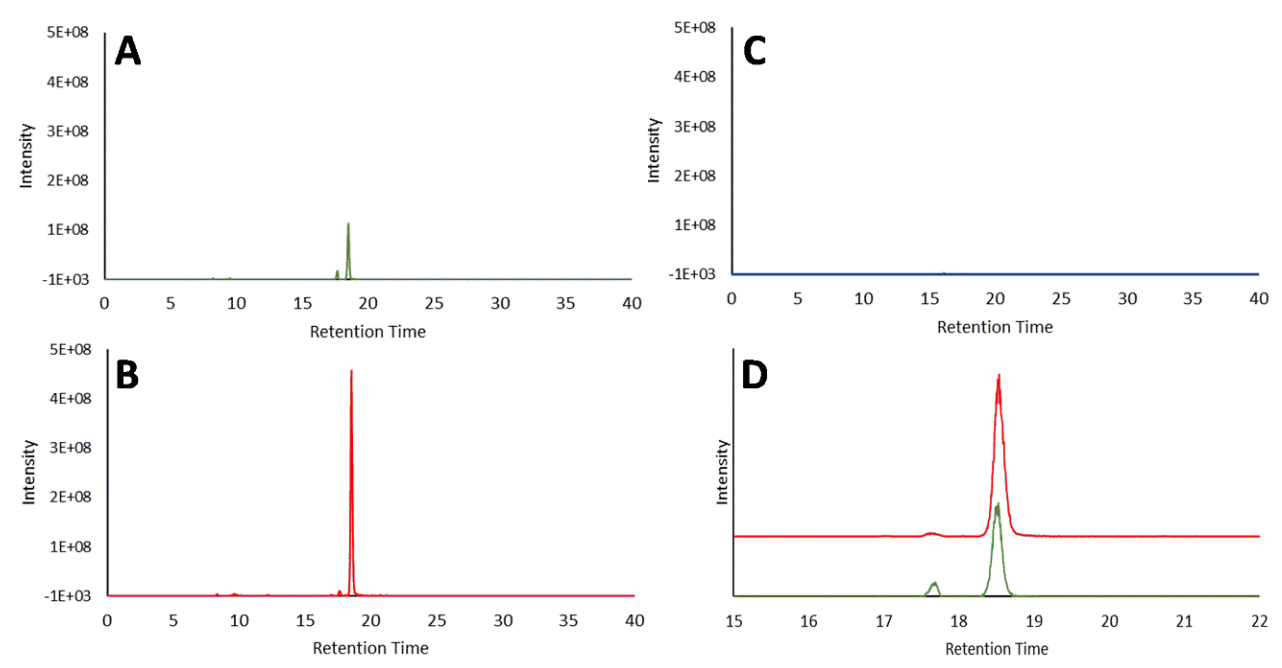

Figure S14. MS/MS of Compound 16

MS/MS Fragmentation for 644.324 Species. Expected product mass of Compound $\mathbf{1 6} \mathrm{m} / z[\mathrm{M}+\mathrm{H}]^{+}$calcd for $\mathrm{C}_{28} \mathrm{H}_{49} \mathrm{~N}_{7} \mathrm{O}_{6} \mathrm{~S}_{2} ; 644.325$. Corresponding fragments are color coded.

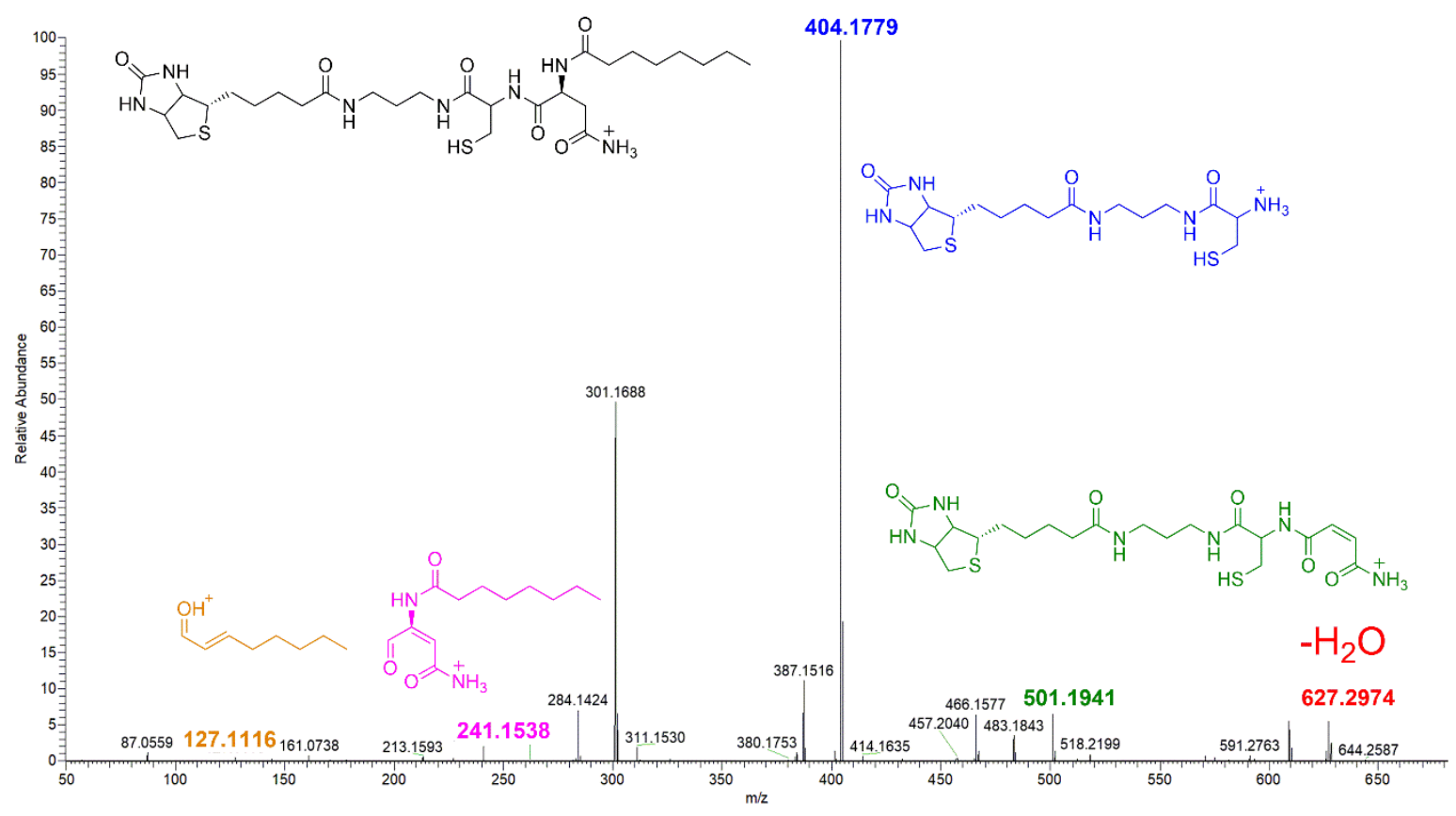


Figure S15. ClbN LC-MS Traces Compound 17

Extracted Ion Chromatograms (EIC) for 627.299. Expected product mass of Compound $\mathbf{1 7} \mathrm{m} / z$ [M+H] $]^{+}$calcd for $\mathrm{C}_{28} \mathrm{H}_{46} \mathrm{~N}_{6} \mathrm{O}_{6} \mathrm{~S}_{2}$; 627.299. A. Biotin-Cys + ClbN Reaction. B. Synthetic Standard of Compound 17. C. Negative Control lacking ClbN protein. D. Overlay of EIC for Biotin-Cys $+\mathrm{ClbN}$ Reaction and Synthetic Standard.
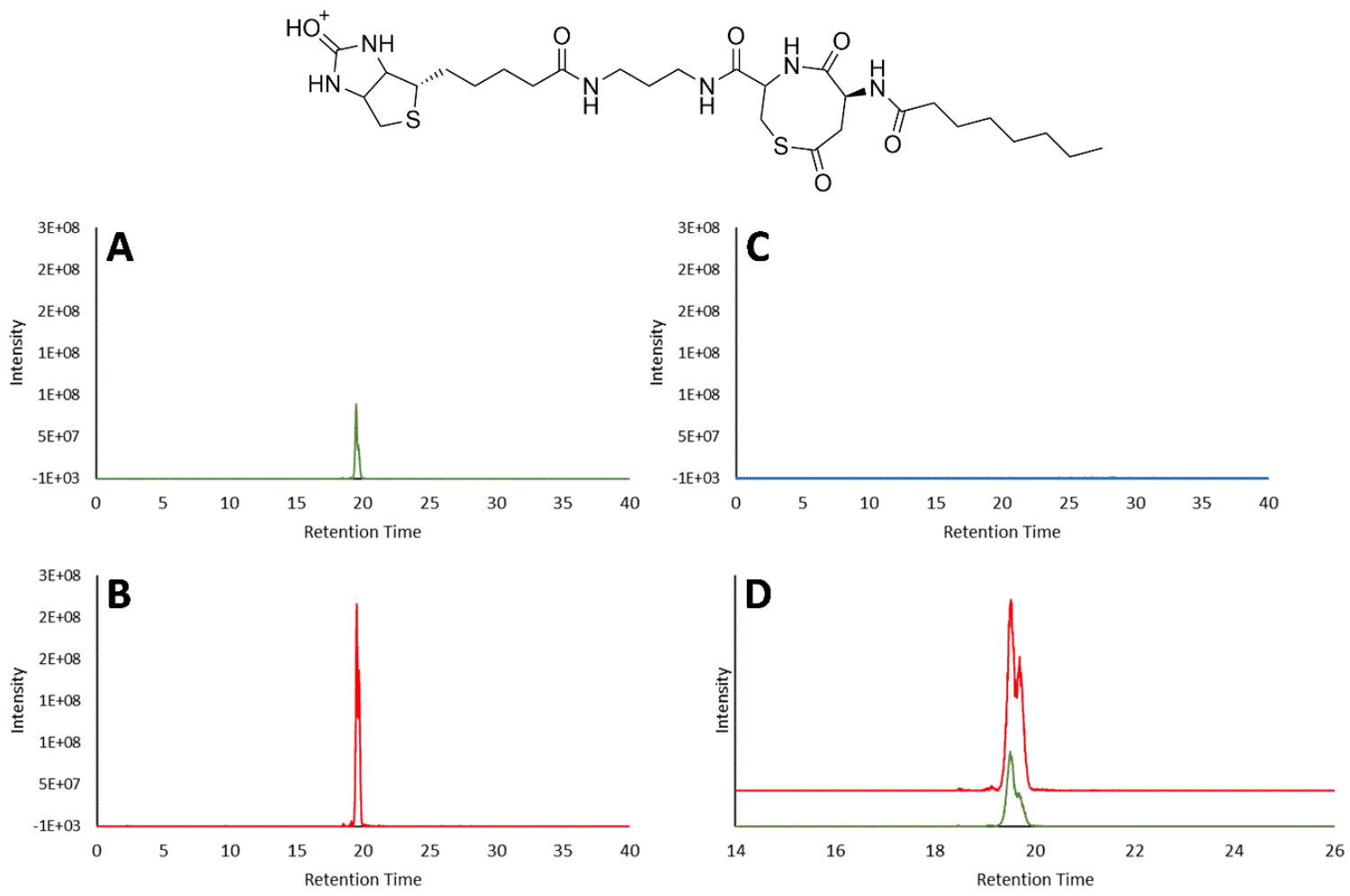

Figure S16. MS/MS of Compound 17

MS/MS Fragmentation for 627.298 Species. Expected product mass of Compound $17 \mathrm{~m} / z \quad[\mathrm{M}+\mathrm{H}]^{+}$calcd for $\mathrm{C}_{28} \mathrm{H}_{46} \mathrm{~N}_{6} \mathrm{O}_{6} \mathrm{~S}_{2}$; 627.299. Corresponding fragments are color coded.

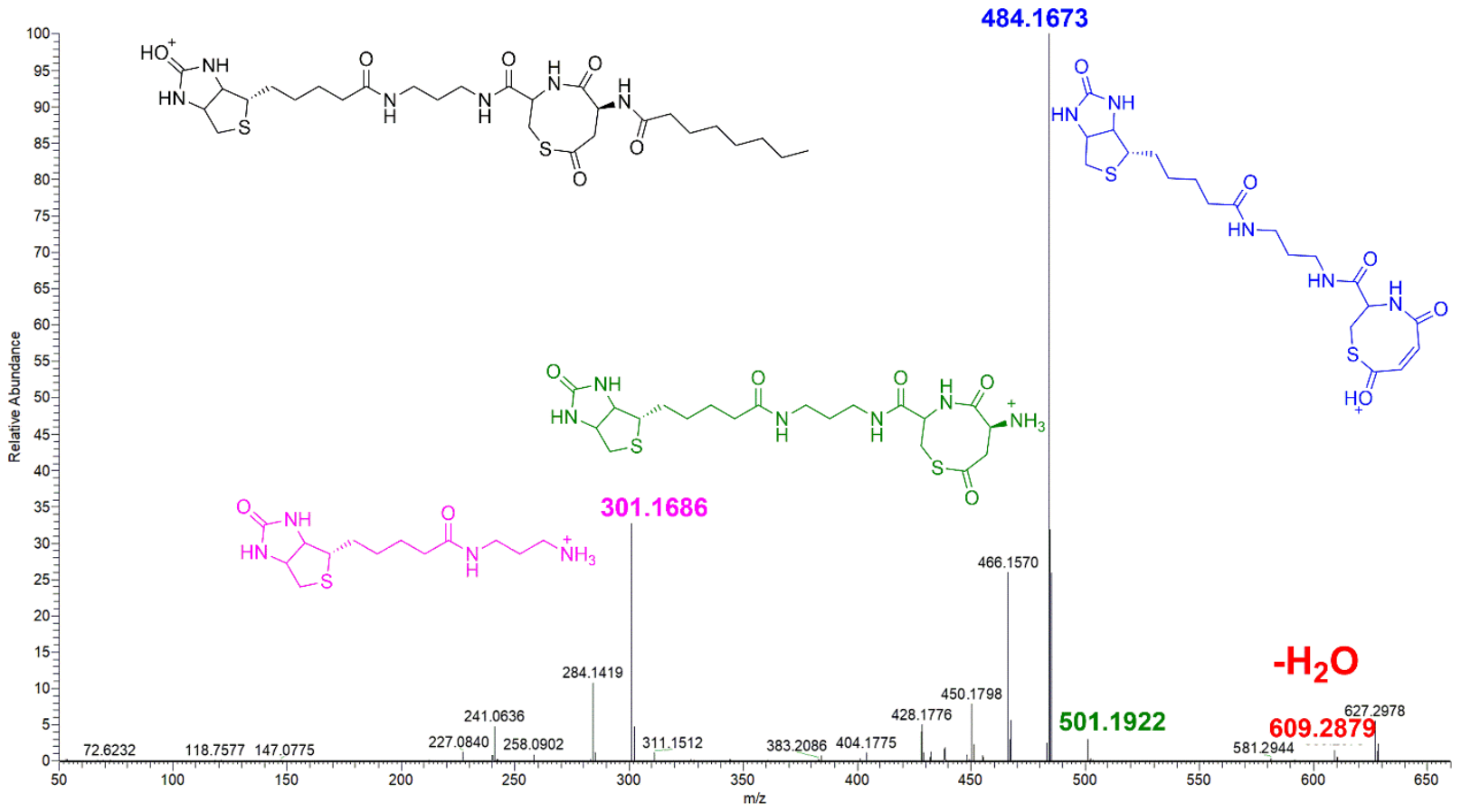




\section{References}

1. Mori, S.; Simkhada, D.; Zhang, H.; Erb, M. S.; Zhang, Y.; Williams, H.; Fedoseyenko, D.; Russell, W. K.; Kim, D.; Fleer, N.; Ealick, S. E.; Watanabe, C. M. H., Polyketide Ring Expansion Mediated by a Thioesterase, Chain Elongation and Cyclization Domain, in Azinomycin Biosynthesis: Characterization of AziB and AziG. Biochemistry 2016,55 (4), $704-714$.

2. Mori, S.; Nepal, K. K.; Kelly, G. T.; Sharma, V.; Simkhada, D.; Gowda, V.; Delgado, D.; Watanabe, C. M. H., Priming of Azabicycle Biosynthesis in the Azinomycin Class of Antitumor Agents. Biochemistry 2017, 56 (6), $805-808$.

3. Lesaicherre, M.-L.; Lue, R. Y. P.; Chen, G. Y. J.; Zhu, Q.; Yao, S. Q., Intein-Mediated Biotinylation of Proteins and Its Application in a Protein Microarray. Journal of the American Chemical Society 2002, 124 (30), 8768-8769.

4. Sharma, V.; Kelly, G. T.; Watanabe, C. M. H., Exploration of the Molecular Origin of the Azinomycin Epoxide: Timing of the Biosynthesis Revealed. Organic Letters 2008, 10 (21), 4815-4818.

5. Gobbo, P.; Gunawardene, P.; Luo, W.; Workentin, M. S., Synthesis of a Toolbox of Clickable Rhodamine B Derivatives. Synlett 2015, 26 (09), 1169-1174.

6. Brotherton, C. A.; Balskus, E. P., A Prodrug Resistance Mechanism Is Involved in Colibactin Biosynthesis and Cytotoxicity. Journal of the American Chemical Society 2013, 135 (9), 3359-3362.

\section{Author Contributions}

L.A.W. planned and performed all of the experiments, except cloning of the pSETAziA3 construct, analyzed the data, and wrote the original draft of the manuscript. K.K.N. cloned the pSETAziA3 construct and assisted L.A.W. in the cloning of the pKCAziA6 construct. C.M.H.W. supervised the project and participated in experiment planning and in writing of the manuscript. 